\title{
IMPLANTAÇÃO DE UM AMBULATÓRIO DE PSICOLOGIA EM UMA UNIDADE DE PRONTO ATENDIMENTO: RELATO DE EXPERIÊNCIA SOBRE A ASSISTÊNCIA À SAÚDE MENTAL DOS PROFISSIONAIS DE SAÚDE DURANTE A PANDEMIA DA COVID-19
}

\section{RELATO DE EXPERIÊNCIA}

SANTANA, Joíza Maria de Oliveira¹, RAMALHO, Renan Enes², NASCIMENTO, Joelma Sampaio do ${ }^{3}$, NASCIMENTO, Pedro Carlos Lira do 4

SANTANA, Joíza Maria de Oliveira. Et al. Implantação de um ambulatório de psicologia em uma unidade de pronto atendimento: relato de experiência sobre a assistência à saúde mental dos profissionais de saúde durante a pandemia da COVID-19. Revista Científica Multidisciplinar Núcleo do Conhecimento. Ano 06, Ed. 07, Vol. 09, pp. 18-30. Julho de 2021. ISSN: 2448-0959, Link de acesso: https://www.nucleodoconhecimento.com.br/psicologia/pronto-atendimento, DOI: 10.32749/nucleodoconhecimento.com.br/psicologia/pronto-atendimento

\section{RESUMO}

Introdução: No ano de 2020 o Brasil enfrentou a primeira onda de contaminação pelo SARS CoV-2 e atualmente vive-se a segunda onda do pico do vírus. Diante disso, praticamente todos os estados brasileiros sofreram um colapso no sistema de saúde com superlotações e filas de espera para tratamento em unidades de terapia intensiva. Os profissionais de saúde foram a primeira classe de trabalhadores a sofrer os impactos desta pandemia devido às vulnerabilidades decorrentes da sua atividade laboral. Problema de pesquisa: Questionou-se como que um serviço de

\footnotetext{
1 Psicóloga residente em Urgência e Emergência pela Residência Multiprofissional COREMU-SESAU.

2 Psicólogo residente em Urgência e Emergência pela Residência Multiprofissional COREMU-SESAU.

${ }^{3}$ Mestre em Psicologia e Coordenadora de área da Psicologia do Programa de Residência em Urgência e Emergência COREMU-SESAU.

${ }^{4}$ Psicólogo Hospitalar Especialista e Preceptor do Programa de Residência Multiprofissional COREMU-SESAU.
}

RC: 91737

Disponível em: https://www.nucleodoconhecimento.com.br/psicologia/pronto- 
plantão psicológico poderia contribuir para minimização dos impactos psicológicos e emocionais, sendo criado um ambulatório psicológico de atendimento aos profissionais de saúde da linha de frente da Unidade de Pronto Atendimento da Zona Sul do município de Porto Velho. Objetivos: O objetivo deste estudo é discorrer sobre a percepção dos autores na construção, implementação e atuação no serviço de Psicologia na unidade municipal visando a promoção da saúde psicoemocional dos profissionais durante este período de crise. Metodologia: A metodologia adotada consistiu em um estudo descritivo, na modalidade de Relato de Experiência. A linha de atendimento utilizada nesse espaço foi embasada na abordagem da psicoterapia breve e formato de plantão psicológico. Resultados: A presença do psicólogo no acolhimento aos profissionais de saúde proporcionou suporte psicológico e emocional com enfoque na prevenção do adoecimento e promoção de saúde dos trabalhadores frente a atual situação pandêmica. Conclusão: Os benefícios de um ambulatório para os profissionais de saúde nas unidades são essenciais para que os mesmos possam cuidar de sua qualidade de vida mesmo diante de uma pandemia.

Palavras-chave: Profissionais de saúde, saúde mental, pandemia, covid-19.

\section{INTRODUÇÃO}

A Organização Mundial da Saúde, em março de 2020, elevou os milhares de casos de infecção pelo novo coronavírus ao status de pandemia devido a sua incidência em várias partes do mundo. Informações eram diariamente divulgadas na mídia com relatos sobre o alto grau de transmissibilidade do vírus, bem como ao adoecimento e agravamento dos pacientes que necessitavam de internação hospitalar e cuidados intensivos. Com os números aumentando em grande magnitude, os profissionais de saúde foram a primeira classe de trabalhadores a sofrer os impactos desta pandemia devido a maior risco de contaminação, exaustão, afastamentos, mortes e desenvolvimento de doenças psíquicas decorrentes da sua atividade laboral.

RC: 91737

Disponível em: https://www.nucleodoconhecimento.com.br/psicologia/pronto- 
Em todo o Brasil, até abril do ano de 2021, foram confirmados 81.574 casos da covid-19 em profissionais da área da saúde. As profissões com maior registro de casos foram técnicos ou auxiliares de enfermagem (24.062) seguido dos enfermeiros (25.718), médicos (8.839), entre outros profissionais de suporte (MINISTÉRIO DA SAÚDE, 2021).

No cenário de crise evidenciado, o profissional de saúde que naturalmente já era exposto às adversidades laborais se vê, no momento atual, frente a desafios ainda maiores no seu campo de atuação. Ornell et al. (2020), identifica alguns desses desafios como:

- Vulnerabilidades e exposição ao vírus.

- O medo de contaminar a si e seus entes queridos.

- Jornadas de trabalho mais longas e exaustivas em razão do afastamento do trabalho de seus pares e até mesmo, a morte destes.

Além disso, devido às novas regras de restrição de visitas e circulação em muitas unidades de saúde, bem como os próprios critérios de isolamento criados para atendimento aos pacientes diagnosticados com COVID-19, o profissional de saúde era o único a estar ao lado destes. O resultado esperado foi um desgaste emocional maior ao ter que evocar múltiplas estratégias de enfrentamento para além de cumprir com sua função técnica, acolher o sofrimento dos pacientes e familiares e ainda administrar seu nível de estresse advindo do acúmulo de deveres. Somam-se a isso, os transtornos psicológicos como a Síndrome de Burnout, ansiedade e depressão que muitas vezes já eram pré-existentes, neste momento, emergem em grande intensidade (ORNELL et al., 2020).

Com esse cenário exposto, questionou-se como que um serviço ambulatorial em saúde mental de acolhimento psicológico poderia contribuir para a minimização dos impactos psicológicos e emocionais dos profissionais de saúde de uma unidade de pronto atendimento.

RC: 91737

Disponível em: https://www.nucleodoconhecimento.com.br/psicologia/pronto- 
Sendo assim, o objetivo deste estudo é discorrer sobre a percepção dos autores na construção, implementação e atuação do serviço de Psicologia em uma unidade municipal visando a promoção da saúde psicoemocional dos profissionais da linha de frente visto que a referida unidade à qual foi ofertado o serviço não dispõe de psicólogos lotados pela Secretaria Municipal de Saúde.

Estudos dentro da linha de atendimento de crise indicam que assistir a pessoa em crise pode prevenir instauração de adoecimento psíquico, estabelecimento de estratégias mais eficazes para lidar com traumas e sua possível elaboração. Cury apud Perches (2009), enfatiza que a oportunidade de receber escuta qualificada em um momento crítico, reduz significativamente o nível de ansiedade e viabiliza a elaboração de respostas adaptativas e enfrentamento positivos para a busca de soluções para a problemática vivenciada.

\section{RELATO DA EXPERIÊNCIA}

Tendo em vista que a Unidade de pronto atendimento da região sul (UPA SUL) da cidade de Porto Velho tornou-se Unidade semi-intensiva, voltada para pacientes infectados pela covid-19 com necessidade de internações por longa data e em aguardo a transferência para outras unidades de referência, foi solicitado por sua coordenadora o suporte psicológico aos profissionais de saúde da linha de frente que atuavam na unidade, visto que era perceptível o sofrimento emocional e desgaste advindos da demanda de trabalho exaustiva, somado a alta taxa de óbitos de pacientes no município de Porto Velho nesse mesmo período.

A partir deste pedido, desenvolveu-se um projeto de extensão elaborado pelos residentes de Psicologia do Programa de Urgência e Emergência da Comissão de Residências Multiprofissionais (COREMU) da Secretária de Saúde do estado de Rondônia (SESAU) para a atuar no campo da Unidade de Pronto Atendimento da UPA SUL.

RC: 91737

Disponível em: https://www.nucleodoconhecimento.com.br/psicologia/pronto- 
A Residência Multiprofissional em Saúde como uma modalidade de pós-graduação, constitui-se como uma forma privilegiada de capacitação em saúde pública, já que prevê o treinamento do profissional voltado para as reais necessidade de saúde da população pelo fato de a prática ser realizada no âmbito do Sistema Único de Saúde (SUS). Destaca-se a importante carga horária teórica e o acompanhamento diário de professores e profissionais experientes do serviço, que subsidiam a integração entre teoria, prática, ensino e serviço de saúde (FILGUEIRAS et al., 2013, p.29).

O projeto de extensão ampliou o serviço de atendimento em saúde promovido pelo Programa de Urgência e Emergência da Residência Multiprofissional em Saúde, expandindo os serviços psicológicos assistenciais à unidade municipal que necessitava do apoio em tempos de pandemia.

A atividade realizada na UPA SUL consistiu na implantação de um ambulatório de Psicologia que visou atender às necessidades psicológicas dos profissionais de saúde atuantes na unidade. De acordo com a metodologia prevista no projeto, o período de atendimento foi de abril à julho do ano de 2021. O critério de inclusão se deu por meio de demanda espontânea na busca destes profissionais pelo serviço de psicologia ofertado, sendo excluso o atendimento a familiares dos mesmos ou a servidores de outras unidades que não fossem da UPA SUL.

Por meio da disponibilização de contato através de um aplicativo de comunicação virtual foi possível realizar os agendamentos das triagens bem como, a marcação de sessões. Esta ferramenta proporciona autonomia pela procura do serviço, visto que reduz a necessidade de exposição do servidor em recorrer ao serviço de psicologia, promovendo maior sigilo mesmo o ambulatório sendo realizado na mesma unidade.

Os atendimentos ocorreram de acordo com as normativas sanitárias vigentes, com uso de máscara obrigatória, como também a utilização de álcool 70 para assepsia das mãos, antes e depois dos atendimentos psicológicos. Os servidores também eram orientados a reagendar ou cancelar os atendimentos caso apresentassem sintomas gripais.

RC: 91737

Disponível em: https://www.nucleodoconhecimento.com.br/psicologia/pronto- 
O atendimento ocorreu no modelo de Plantão Psicológico com encontros individuais e presenciais com tempo de duração de 50 minutos cada. O plantão psicológico surgiu como uma ferramenta institucional que visava assistência psicológica e emocional em um contexto de urgência, por meio da prática de escuta qualificada e suporte em sessão única, podendo estender-se a mais atendimentos conforme a necessidade do indivíduo (CURY, 2012).

Para Perches (2009) a expressão denominada plantão remete a uma modalidade de atendimento em que um profissional está à inteira disposição de quaisquer pessoas que necessitem de seus serviços, em períodos de tempo previamente determinados e ininterruptos.

Cury apud Perches (2009) afirma que o plantão psicológico representa uma flexibilização às formas convencionais de atendimento clínico ofertados à população como dispositivo de promoção de saúde, pois torna comum um serviço muitas vezes elitizado, como ainda representa o acesso ao atendimento psicológico.

Por conseguinte, o plantão psicológico mostra-se como um tipo de atenção que não é de maneira alguma rígido, pois concebe o sujeito como um ser em constante transformação e que admite que suas potencialidades e capacidade de adaptação possam ser aprimoradas mediante as exigências e desafios do meio em que vive (PERCHES, 2009).

Nesse sentido, a autora supracitada afirma que a ação terapêutica do plantão psicológico irá depender da atitude volitiva do paciente e seu objetivo não é a resolutividade das suas demandas, mas sim a amplitude na compreensão das questões que ocasionam sofrimento para que possa buscar recursos internos e manejar as situações, e assim, proporcionar o alívio psicológico.

As sessões foram pautadas nas técnicas da Psicoterapia breve, as quais serviram de instrumentos pontuais no suporte psicológico. Esta abordagem foi escolhida por

RC: 91737

Disponível em: https://www.nucleodoconhecimento.com.br/psicologia/pronto- 
permitir que os psicoterapeutas juntamente com os pacientes estabelecessem um foco a ser trabalhado após a hierarquização da problemática trazida e, dessa forma, traçar metas e objetivos a serem alcançados.

Lemgruber (1987) define a Psicoterapia breve como uma técnica específica, com características próprias, o que não significa simplesmente o encurtamento de um processo terapêutico. Embora esta abordagem possibilite atingir os objetivos terapêuticos em período mais reduzido do que o das abordagens convencionais.

A autora acima mencionada expõe que os fatores que especificam a psicoterapia breve consistem na técnica focal que é representada pela tríade: planejamento, atividade e foco, e ainda a vivência de "experiências emocionais corretivas" (EEC) nas sessões terapêuticas.

Esta tríade em Psicoterapia breve refere-se a atitude deliberadamente mais ativa do terapeuta em relação ao paciente, dissonante da postura passiva e neutra da psicanálise. O objetivo da EEC seria desfazer interpretações disfuncionais e dar novo sentido a estes eventos, corrigindo a experiência em níveis cognitivos e emocionais.

A dinâmica de atendimentos foi iniciada primeiramente com entrevistas de anamnese voltadas para a coleta de informações psicossociais como: idade, função laboral, tempo de serviço, escala laboral, existência de mais de um vínculo empregatício, informações referentes a família, lazer etc.

Com os dados obtidos por meio da escuta ativa, foram desenvolvidos planos de tratamentos breves, focados no problema trazido pelo paciente. Nos casos em que foram percebidos cronicidade de sintomas, adotou-se o procedimento de realizar encaminhamentos para avaliação e conduta psiquiátrica, concomitantemente, ao processo psicoterápico.

RC: 91737

Disponível em: https://www.nucleodoconhecimento.com.br/psicologia/pronto- 
Após cada atendimento era realizado o registro das sessões com informações pertinentes às observações dos psicoterapêutas frente às demandas psicológicas e emocionais trazidas. Este registro facilitava a possibilidade de formulação de estratégias psicoterápicas para os encontros posteriores.

Atinente a periodicidade, o consultório ficou disponível em dias pré-determinados para a realização das sessões. A maioria dos encontros foram realizados na sala do NEP (Núcleo de Educação Permanente) da referida unidade. Como estratégias de divulgação da ação foram criados folders virtuais informativos sobre o serviço ofertado.

Após a finalização da implementação do ambulatório, elaborou-se um relatório de devolutiva para a Unidade beneficiada pelo serviço de Psicologia, pautado no sigilo profissional. Este relatório compreende informações referentes à quantidade de pessoas atendidas, bem como a percepção geral dos atendimentos sucedidos e sugestões de ações psicoeducativas a serem realizadas, visando fomentar a saúde emocional dos colaboradores.

\section{DISCUSSÃO}

O serviço de Psicologia dentro da UPA SUL consistiu na criação de "espaços de escuta" com objetivo de atender as demandas psicoemocionais, bem como na prevenção e minimização do adoecimento psíquico dos profissionais de saúde que atuam na linha de frente do cuidado ao pacientes em tratamento da Covid-19.

Mahfoud (1987) sustenta que um dado espaço de escuta pode evitar a cronicidade de fenômenos psicológicos deletérios à medida que o psicólogo na relação terapêutica ofereça atenção e acolhimento em caráter emergencial ao sujeito que de forma espontânea buscou ajuda.

RC: 91737

Disponível em: https://www.nucleodoconhecimento.com.br/psicologia/pronto- 
Nos atendimentos realizados foi possível perceber sentimentos de ambivalência nos servidores, pois afirmavam que o trabalho lhes trazia satisfação, entretanto também era acompanhado de uma carga de sofrimento em decorrência da sua atividade laboral.

Dejours (2015) afirma que o trabalho está atrelado à identidade do indivíduo e, sendo assim, torna-se indissociável do seu afeto e qualidade de vida. Ademais, este não representa somente a fonte de suprimento vital, mas em sintonia com aspectos emocionais e psíquicos, corresponde a uma fonte de prazer e de realização para o trabalhador. Todavia, por vezes, as circunstâncias do trabalho são desfavoráveis podendo provocar deformações no equilíbrio físico e emocional do trabalhador.

As queixas mais comuns percebidas envolviam contexto de luto por perda de familiares, colegas de trabalho, dificuldades em lidar com óbitos dos pacientes na assistência, sentimentos de compaixão pelos pacientes internados, o medo de ser infectado ou reinfectado, recurso de tempo escasso para dedicar-se a vida pessoal e familiar, e ainda a percepção de sequelas pós-covid e de como estas impactam na qualidade de vida destes servidores. Além disso, temáticas referentes a dificuldades de relacionamento interpessoal no trabalho e questões familiares foram consideradas.

Foram observados nos atendimentos queixas de estados afetivos dos servidores como tristeza, irritabilidade e medo intenso; sintomas orgânicos como alterações do sono, aumento e diminuição do apetite, falta de energia, cansaço; alterações de ordem psíquica como dificuldade de concentração, tomar decisões, atenção diminuída ou estado de alerta constantes; como também, comportamentos de esquiva do ambiente de trabalho e absenteísmo. Nesta perspectiva, Zanelli (2010) enfatiza que a atividade laboral por vezes se configura como um fio condutor para o surgimento de doenças psíquicas devido a fatores como desgaste, excesso de demandas e pressões existentes nas organizações.

RC: 91737

Disponível em: https://www.nucleodoconhecimento.com.br/psicologia/pronto- 
Zanelli (2010), declara ainda que o desgaste físico e emocional advindos do trabalho são o substrato para o surgimento de doenças físicas e psicológicas, pois ocasiona na perda da capacidade psíquica e biológica do indivíduo de manejar situações e garantir a homeostase.

Não obstante, acredita-se que tais fenômenos psicológicos e comportamentais observados nestes servidores durante os atendimentos, não podem ser reduzidos somente como consequências do advento da pandemia, mas que as circunstâncias psicoemocionais vivenciadas no ambiente laboral, acrescidas de particularidades pessoais intrínsecas já existiam, mas eram veladas, e devido ao contexto de crise instaurado, foram manifestas trazendo desestabilização emocional e dificuldades no manejo de estratégias salutares de enfrentamento.

Diante disso, as intervenções psicoterápicas tiveram como foco o fortalecimento dos recursos pessoais de enfrentamento do servidores, pois ao receber esse suporte constatou-se o aprimoramento da capacidade interna em desenvolver estratégias defensivas satisfatórias que possibilitaram discursos referentes ao alívio de sintomas e minimização do sofrimento, e consequentemente na redução da possibilidade de adoecimento.

Cabe ressaltar que o suporte psicológico desenvolvido no ambulatório de Psicologia na Unidade favoreceu o acolhimento e a identificação de demandas psicológicas pelos próprios servidores, pois em alguns atendimentos traziam um estado emocional no qual não conseguiam localizar a sua origem e por meio da escuta terapêutica e intervenções, que proporcionaram autoconhecimento e compreensão do próprio funcionamento, puderam potencializar suas percepções sobre si.

Nesse sentido, Perches (2009) refere sobre a disponibilidade e capacidade do psicólogo para assimilar a demanda e necessidade da pessoa que está em sofrimento. Constitui-se assim, em uma relação (eu-tu) na qual o terapeuta propicia

RC: 91737

Disponível em: https://www.nucleodoconhecimento.com.br/psicologia/pronto- 
um ambiente psicológico seguro e permite que o indivíduo reconheça suas angústias.

Nessa discussão é importante salientar sobre a relevância da implantação do ambulatório de saúde mental em atenção aos servidores da UPA SUL, porquanto estes servidores não dispunham de assistência psicológica ofertada pelo município em uma fase crítica no ambiente de trabalho. Todavia, independente do período, é imprescindível a presença do psicólogo nas Unidades de Pronto Atendimento, pois este pode contribuir na prevenção do adoecimento mental quando oferta espaços de escuta tanto aos servidores quanto para pacientes assistidos na Unidade, prezando sempre pela promoção da saúde na sua atuação.

Ademais, as potencialidades do Psicólogo dentro da UPA não se restringem somente ao atendimento ambulatorial individualizado, mas dentro deste escopo pode-se utilizar inúmeras estratégias, como trabalhar grupos terapêuticos, oficinas de promoção do autocuidado, rodas de conversa, palestras, entre outras.

Apesar da boa demanda do ambulatório, notou-se resistência na procura pelo serviço. Outrossim, era perceptível que ao entrar em contato via plataforma digital para marcação da primeira sessão, os solicitantes queriam se certificar que o serviço ofertado seria realizado por profissionais já formados e não por estagiários. Além disso, percebeu-se que alguns servidores chegavam à sessão receosos e, em alguns momentos, ouviu-se verbalizações do tipo: "Eu não sei como vou conseguir falar de mim para uma pessoa estranha" (sic). Nesse momento os psicoterapeutas procuravam ser empáticos e investir na formação da aliança terapêutica.

Outro desafio na execução da atividade foram relacionados a conteúdos trazidos pelos servidores que vinham de encontro às demandas dos psicoterapeutas, principalmente aqueles voltados para medos e incertezas gerados pela pandemia. Além disso, os psicoterapeutas sentiram-se muitas vezes expostos por estarem atendendo em uma Unidade que na ocasião era referência para pacientes

RC: 91737

Disponível em: https://www.nucleodoconhecimento.com.br/psicologia/pronto- 
infectados com COVID-19 emergindo nos psicólogos sentimentos de apreensão e medo. Entretanto, estes conteúdos eram então trabalhados em supervisão.

A empatia, ao mesmo tempo que se mostrava como uma ferramenta para que os psicólogos se conectassem emocionalmente com os indivíduos atendidos, proporcionava experienciar a dor do outro, que compartilhada naquele espaço se tornava de alguma forma, parte dos psicoterapeutas. Infere-se, que o sofrimento dos trabalhadores atendidos na Unidade impactaram emocionalmente os psicólogos. Entretanto, este impacto não foi empecilho para lhes prestar o acolhimento e a realização do tratamento psicológico.

Outra dificuldade encontrada referiu-se a logística da Unidade, pois muitas vezes o espaço que estava destinado para os atendimentos encontrava-se ocupado em decorrência de cursos e treinamentos na Unidade. Nesse contexto, precisou-se buscar alternativas que viabilizassem a execução da atividade proposta, e então, procurava-se um local reservado onde se pudesse preservar o sigilo, condição indispensável para a realização dos atendimentos.

A finalização de alguns atendimentos individuais se deu mediante iniciativa do próprio paciente após ter tido suas queixas focais trabalhadas. Percebia-se por meio das palavras suas angústias serem diluídas e acolhidas, muitas vezes em um único encontro.

Em contrapartida, outros se estenderam para sessões semanais de acordo com a necessidade trazida pelos pacientes. Nesse sentido, Perches (2009) define que o fim do processo psicoterápico dependerá da pessoa que procurou atendimento. Observando se a queixa foi ressignificada ou houve o aumento da percepção quanto à problemática vivenciada.

Ainda assim, não houve tempo hábil para serem trabalhados todos os pontos da hierarquização da problemática que alguns servidores trouxeram como queixa, por

RC: 91737

Disponível em: https://www.nucleodoconhecimento.com.br/psicologia/pronto- 
isso, ao encerrar o ambulatório do Serviço de Psicologia na Unidade foi comunicado previamente aos servidores e realizada orientações ou encaminhamentos necessários para a continuidade dos atendimentos sistemáticos.

\section{CONSIDERAÇÕES FINAIS}

Diante do contexto pandêmico urge-se a necessidade do profissional de saúde ter validado o seu sofrimento e receber o acolhimento tão necessário para a prática do seu fazer, que implica no cuidar do outro.

Constata-se que é importante sensibilizar e atrair o olhar da sociedade, sobretudo dos órgãos governamentais para os impactos psicoemocionais destes servidores que tem apresentado sintomas de adoecimento e sequelas emocionais intensificadas pelo ambiente ocupacional.

Por conseguinte, não somente na assistência aos pacientes e familiares como já é preconizado na saúde, mas de um modo geral, é imprescindível a presença do psicólogo dentro das unidades de saúde na atenção à saúde mental dos servidores, pois a sua prática é orientada a minimização do sofrimento psíquico e emocional dos indivíduos.

Finalmente, a experiência dos atendimentos no ambulatório proporcionou aos psicólogos residentes um sentimento de contentamento ao contribuir com a promoção de saúde mental e a oferta de um espaço de escuta dentro da UPA SUL. Trazer um modelo assistencial de setting terapêutico aos profissionais de saúde desta Unidade em um cenário de crise foi recompensador e acredita-se ser um avanço da Psicologia dentro de um lugar ainda não ocupado pelo psicólogo no município de Porto Velho. Destaca-se a contribuição da Residência Multiprofissional por abrir portas para a atuação da Psicologia tão necessária nesse campo.

\section{REFERÊNCIAS}

RC: 91737

Disponível em: https://www.nucleodoconhecimento.com.br/psicologia/pronto- 
CURY, V. E. Plantão psicológico em clínica-escola. In: MAHFOUD, M. Plantão psicológico: Novos horizontes. São Paulo: Editora Companhia ilimitada, p. 115133, 2012.

DEJOURS, C. A Loucura do trabalho: estudo de psicopatologia do trabalho. ed. 06, São Paulo: Cortez, 2015.

FILGUEIRAS, M. S. T.; et al. Residência em Psicologia: Novos contextos e desafios para a formação em saúde. Petrópolis, RJ: Vozes, 2013.

MAHFOUD, M. A Vivência de um desafio: plantão psicológico. In: ROSENBERG, R. L. Aconselhamento Psicológico Centrado na Pessoa. São Paulo: EPU, p. 7583, 1987.

MINISTÉRIO DA SAÚDE. Ministério da saúde divulga dados epidemiológicos da covid-19. Brasília, 2021. Disponível em: <https://www.gov.br/saude/ptbr/assuntos/noticias/ministerio-da-saude-divulga-dados-epidemiologicos-da-covid19-1>. Acesso em: 08 jun. 2021.

ORNELL, F. et al. $O$ impacto da pandemia de COVID-19 na saúde mental dos profissionais de saúde. Cadernos de Saúde Pública, Rio de Janeiro, v. 36, n. 4, abril 2020. Disponível em: <http://cadernos.ensp.fiocruz.br/csp/artigo/1037/oimpacto-da-pandemia-de-covid-19-na-saude-mental-dos-profissionais-desaude>. Acesso em: 09 jul. 2021.

PERCHES, T. H. P. Plantão psicológico: o processo de mudança psicológica sob a perspectiva da psicologia humanista. 2009. Tese (doutorado) - Programa de Pós-Graduação em Psicologia, Pontifícia Universidade Católica de Campinas, 2009.

PREFEITURA DE PORTO VELHO. Prefeitura de Porto Velho aumenta capacidade de atendimento de emergência. Roteiro Amazônico, Rondônia, 06 jun.

RC: 91737

Disponível em: https://www.nucleodoconhecimento.com.br/psicologia/pronto- 
2020.

Disponível

em:

$<$ https://www.portalroteiroamazonico.com.br/site/noticia/prefeitura-de-porto-velhoaumenta-capacidade--de-atendimento-de-emergencia/>. Acesso em: 09 jun. 2021.

ZANELLI, J. C. Estresse nas organizações de trabalho: compreensão e intervenção baseadas em evidências. Porto Alegre: Artmed, 2010.

Enviado: Julho, 2021.

Aprovado: Julho, 2021.

RC: 91737

Disponível em: https://www.nucleodoconhecimento.com.br/psicologia/prontoatendimento 